\title{
The influence of wheat bran and pectin on the distribution of water in rat caecal contents and faeces
}

\author{
BY ELIZABETH F. ARMSTRONG, MARTIN A. EASTWOOD \\ AND W. GORDON BRYDON \\ Gastrointestinal Unit, University Department of Medicine, Western General Hospital, \\ Edinburgh EH4 $2 X U$
}

(Received 26 February 1992 - Accepted 5 August 1992)

\begin{abstract}
Wheat bran and pectin $(100 \mathrm{~g} / \mathrm{kg})$ were added to a basal diet and fed to rats. An in vitro dialysis technique was used to measure the distribution of caecal and faecal water between the bound, i.e. that held by bacteria and undigested macromolecules, and free water. Bran increased wet $(67 \%)$ and dry $(74 \%)$ faecal weight. Pectin increased wet faecal weight $(59 \%)$, but did not influence dry weight. In faeces both bran and pectin increased the amount of total and bound water, but only pectin increased total and bound water when expressed on a dry weight basis. Caecal wet $(90 \%)$ and dry $(67 \%)$ weights increased with pectin but not with bran. Bran did not change total water but increased bound water whereas pectin increased both. This suggests that water contributed more to the increase in stool bulk in the pectinsupplemented animals due to free and bound water associated with both increased numbers of bacteria and residual pectin. Pectin altered the distribution of water in faeces. Bran has no effect on water distribution and is only partly fermented. The residual water-holding capacity leads to an increased wet and dry stool output.
\end{abstract}

Dietary fibre: Caecal water: Faecal water: Rat

Differences in daily stool weight, $100-300 \mathrm{~g}$ on the average Western diet (Eastwood et al. 1982) and 400-500 $\mathrm{g}$ for the rural African, are a reffection mainly of the fibre content of the diet (Burkitt et al. 1972). The physical properties of fibre are important when explaining how fibre behaves in the gastrointestinal tract. Water-holding capacity (WHC), i.e. the ability of fibre to immobilize water, has been of particular interest in determining the influence different fibres have in the gastrointestinal tract (Eastwood et al. 1983; Tomlin \& Read, 1988).

However, an inverse relationship has been demonstrated between pre-ingestion WHC and effect on stool weight (Stephen \& Cummings, 1980 a). This is probably because watersoluble fibres which have the highest WHC are extensively fermented by the bacteria in the colon resulting in a loss of WHC. Recently the residual WHC of a fibre after a $24 \mathrm{~h}$ in vitro fermentation with faecal bacteria has been shown to give a better correlation with daily stool output (McBurney et al. 1985).

Faeces are a complex, heterogeneous mixture of bacteria, food residues, soluble ions, organic compounds, endogenous substances (mucus) and water. The average stool is approximately $75 \%$ water, by weight, in man, but somewhat drier in rats (60-70\%). Some of this water is free but the majority is unavailable for absorption and this is mainly distributed between the bacterial and fibre components of the faeces. It has previously been shown, using a stool fractionation technique (Stephen \& Cummings, 1980b) that fibre can either increase stool weight by the residual WHC (unfermentable fibre) or by proliferation 
of bacteria (fermentable fibre), which on average account for about $55 \%$ of the dry faecal weight.

In the present study the influence of wheat bran and pectin on the distribution of water in rat caecal and faecal material has been investigated using an in vitro suction method (Robertson \& Eastwood, 1981). These were chosen as representing a rapidly fermented non-starch polysaccharide (pectin) and a minimally fermented non-starch polysaccharide source (wheat bran; Stephen \& Cummings, 1980c). Since bacterial fermentation of fibre and bacterial mass can significantly influence the water content of caecal and faecal material, short-chain fatty acids (SCFA) and 2,6-diaminopimelic acid (DAPA) contents have also been determined.

\section{MATERIALS AND METHODS}

\section{Animals and diets}

The basal diet (Special Diets Services, Witham, Essex) was of plant origin (g/kg: soya-bean concentrate 200; soya-bean oil 30; maize flour 720; nutritionally complete vitamin and mineral premix 50) and contained $(\mathrm{g} / \mathrm{kg})$ non-starch polysaccharide (NSP; Englyst \& Cummings, 1988) 45 and starch with a negligible resistant-starch content 492 . The two dietary fibres used as supplements were high-methoxyl pectin-USP derived from citrus peel (H. P. Bulmer Ltd, Hereford; $964 \mathrm{~g} \mathrm{NSP} / \mathrm{kg}$ ) and coarse Canadian Red Spring Wheat bran (Chancelot Mills, Edinburgh, Scotland; $463 \mathrm{~g} \mathrm{NSP} / \mathrm{kg}$; Table 1). Sieving tests of this material (sieve aperture size) showed it to have the following distribution of particle sizes (aperture size (mm) and percentage of bran passing through the sieve, respectively: $3 \cdot 55,1$; $2 \cdot 8,4 \cdot 1 ; 1 \cdot 5,46 \cdot 1 ; 0 \cdot 75,31 \cdot 5 ; 0 \cdot 5,17 \cdot 3)$.

Albino Wistar rats were bred in the Animal Unit, Western General Hospital, Edinburgh. Before experimentation, adult rats were maintained on a stock chow diet (CRM(X); Special Diet Services; $133 \mathrm{~g} \mathrm{NSP} / \mathrm{kg}$ ).

Male rats aged 6 weeks were divided into three groups of six, housed in pairs, and fed on the basal diet, or basal diet supplemented with $100 \mathrm{~g}$ either wheat bran or pectin $/ \mathrm{kg}$ added to the diet for $28 \mathrm{~d}$.

Animals were housed in solid-bottomed cages with white-wood shavings for bedding. The room was regulated to a $12 \mathrm{~h}$ light $-12 \mathrm{~h}$ dark schedule, maintained at $20^{\circ}$. Diets were prepared daily. Dry weights of diets were recorded and mixed with a known amount of tap water to form a stiff paste and presented in stainless-steel bowls. Food and water were provided ad lib.

General health was assessed regularly and increases in body weight were used as an indication of good health. Assessment of daily food intake was determined from left-over food and calculated on a dry weight basis. Rats were transferred to individual metabolism cages $7 \mathrm{~d}$ before the end of the experiment. At the end of this time the animals were killed by diethyl ether anaesthesia.

\section{Sample collection}

Faeces. Total faecal output of each animal was collected during the three final consecutive $24 \mathrm{~h}$ periods, weighed and stored at $-20^{\circ}$. In addition, freshly voided faeces were collected throughout the day, weighed, frozen at $-20^{\circ}$, freeze-dried and reweighed to determine the water content. Faeces left under comparable conditions, i.e. left at room temperature on a bench, lost only $8 \%$ of their water content over a $24 \mathrm{~h}$ period. However, wet weight was calculated on the basis of samples taken within $1 \mathrm{~h}$ of passage.

Caecal contents. After the animals had been killed by diethyl ether anaesthesia, the abdomen was opened, the caecum was isolated, dissected out, transferred to a preweighed vial and weighed. The caecum was opened and the caecal contents scraped into a 
Table 1. Fibre content of diet and supplements

(Values are expressed as non-starch polysaccharides (Englyst \& Cummings, 1988) in the diet (g/kg dry weight)

\begin{tabular}{|c|c|c|c|c|c|c|c|c|c|}
\hline & \multicolumn{3}{|c|}{ Basal diet } & \multicolumn{3}{|c|}{ Wheat bran } & \multicolumn{3}{|c|}{ Pectin } \\
\hline & Total & Soluble & Insoluble & Total & Soluble & Insoluble & Total & Soluble & Insoluble \\
\hline Cellulose & $\operatorname{Tr}$ & - & $\operatorname{Tr}$ & 105 & - & 105 & 2 & - & 2 \\
\hline $\begin{array}{l}\text { Non-cellulose } \\
\text { polysaccharides }\end{array}$ & 45 & 14 & 31 & 358 & 48 & 310 & 962 & 955 & 7 \\
\hline Rhamnose & 1 & $\operatorname{Tr}$ & 1 & $\operatorname{Tr}$ & $\operatorname{Tr}$ & $\operatorname{Tr}$ & 17 & 17 & $\operatorname{Tr}$ \\
\hline Fucose & 1 & 1 & $\operatorname{Tr}$ & $\operatorname{Tr}$ & $\operatorname{Tr}$ & $\operatorname{Tr}$ & $\operatorname{Tr}$ & $\operatorname{Tr}$ & $\operatorname{Tr}$ \\
\hline Arabinose & 7 & 2 & 5 & 103 & 7 & 96 & 18 & 15 & 3 \\
\hline Xylose & 3 & $\mathrm{Tr}$ & 3 & 191 & 23 & 168 & 5 & 4 & 1 \\
\hline Mannose & 2 & 1 & 1 & 3 & $\mathrm{Tr}$ & 3 & 4 & 4 & $\operatorname{Tr}$ \\
\hline Galactose & 11 & 4 & 7 & 9 & 3 & 6 & 50 & 49 & I \\
\hline Glucose & 11 & 2 & 9 & 33 & 9 & 24 & 12 & 12 & $\operatorname{Tr}$ \\
\hline Uronic acid & 9 & 5 & 4 & 19 & 6 & 13 & 856 & 854 & 2 \\
\hline Total & 45 & 14 & 31 & 463 & 48 & 415 & 964 & 955 & 9 \\
\hline Total starch*: Mean & 492 & & & 52 & & & & & \\
\hline SE & 7 & & & 1 & & & & & \\
\hline \multirow{2}{*}{$\begin{array}{c}\text { Resistant starch*: Mean } \\
\text { SE }\end{array}$} & \multirow{2}{*}{\multicolumn{2}{|c|}{ negligible }} & & 6 & & & & & \\
\hline & & & & 3 & & & & & \\
\hline
\end{tabular}

Tr, trace.

* Siljestrom \& Asp (1985) method.

preweighed vial, weighed and stored at $-20^{\circ}$. Weight of contents was calculated by subtraction of empty from full caecum weights to allow for loss of material during manipulation.

\section{Preparation of samples}

Faecal and caecal samples were divided into roughly equal portions and half stored at $-20^{\circ}$ for water-holding studies and half adjusted to $>\mathrm{pH} \mathrm{9,} \mathrm{frozen} \mathrm{and} \mathrm{freeze-dried,} \mathrm{for}$ SCFA (Spiller et al. 1988) and DAPA (Czerkawski, 1974) analysis, with the following modifications: (a) for the hydrolysis procedure, culture tubes with screw caps were placed in a hot block at $105^{\circ}$. (b) Amberlite CG - $120(\mathrm{Na})$, mesh size 100-120, supplied by Fluka (UK agents: Fluorochem Ltd, Glossop, Derbyshire) was used as the ion-exchange resin.

\section{Suction method for WHC (bound water)}

Dialysis tubing (Medicell International Ltd, London) size 4-22/32 in was cut into $100 \mathrm{~mm}$ lengths and soaked overnight in a solution of sodium azide $(1 \mathrm{~g} / 1)$. One end of the bag was tied with waxed dental floss. Fresh faecal and caecal materials were hydrated overnight in a solution of sodium azide and portions (equivalent to $100 \mathrm{mg}$ dry weight) placed into the dialysis tubing followed by sodium azide solution $(1 \mathrm{~g} / 1)$. The other end of the dialysis tubing was tied off before placing the bag into a $150 \mathrm{ml}$ (Eastwood et al. 1983) conical flask. Polyethylene glycol (PEG 10000 (BDH Chemicals, Poole, Dorset); $50 \mathrm{ml}$; Eastwood et al. 1983) of known osmolality was added to each flask. Suction pressures of $2 \mathrm{~atm}$ $(89 \mathrm{mosm} / 1)$ and $4 \mathrm{~atm}(178 \mathrm{mosm} / \mathrm{l})$ were produced by adding 100 and $148 \mathrm{~g}$ PEG $10000 / 1$ sodium azide solution respectively. A dialysis bag with sodium azide solution $(\mathrm{lg} / \mathrm{l})$ was used as a control, Flasks were sealed and shaken in an orbital shaker at room temperature. After $72 \mathrm{~h}$ the bags were removed, blotted, placed in a dry sealed universal vial and weighed. The wet weight of the sample was determined by subtracting the weight of both the wet bag and vial. The bag was cut open, placed in a weighed universal vial, 
Table 2. Water-holding capacity (WHC) of wheat bran and pectin measured by the suction method $\uparrow$

(Mean values with their standard errors for triplicate observations)

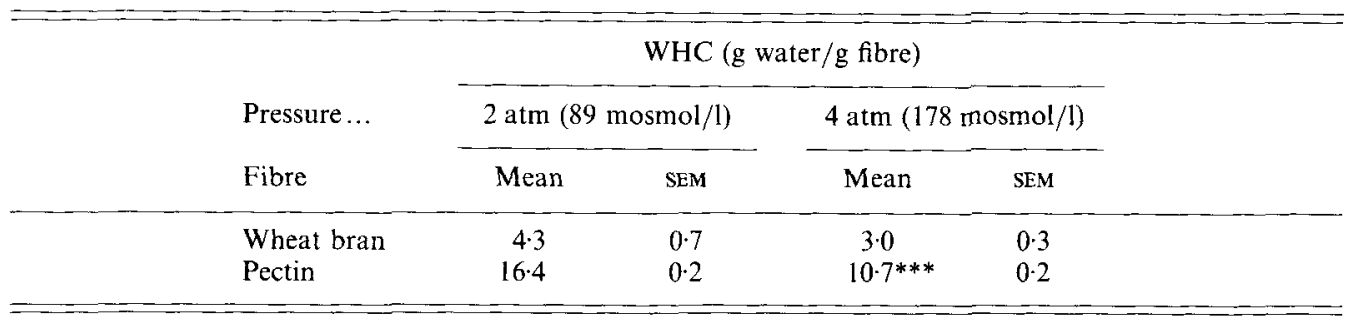

Mean values are significantly different from those at 2 atm (unpaired $t$ test): ${ }^{* * *} P<0 \cdot 001$.

+ For details of procedures, see pp. 915-916.

Table 3. The influence of wheat bran and pectin $(100 \mathrm{~g} / \mathrm{kg})$ on wet and dry weight, total and bound water, short-chain fatty acids (SCFA) and 2,6-diaminopimelic acid (DAPA) in faeces $\dagger$ (Mean values with their standard errors for six observations)

\begin{tabular}{|c|c|c|c|c|c|c|}
\hline \multirow[t]{2}{*}{ Diet... } & \multicolumn{2}{|c|}{ Basal } & \multicolumn{2}{|c|}{+ Bran } & \multicolumn{2}{|c|}{+ Pectin } \\
\hline & Mean & $\mathrm{SE}$ & Mean & $\mathrm{SE}$ & Mean & $\mathrm{SE}$ \\
\hline Wet wt $(\mathrm{g} / \mathrm{d})$ & $3 \cdot 3$ & $0 \cdot 4$ & $5 \cdot 4^{* *}$ & 0.1 & $5 \cdot 2^{* *}$ & $0 \cdot 3$ \\
\hline Dry wt $(\mathrm{g} / \mathrm{d})$ & $1 \cdot 3$ & $0 \cdot 1$ & $2 \cdot 2^{*}$ & $0 \cdot 1$ & 1.5 & $0 \cdot 1$ \\
\hline Total water $(\mathrm{g} / \mathrm{g}$ dry wt) & $1 \cdot 6$ & $0 \cdot 1$ & $1 \cdot 5$ & $0 \cdot 1$ & $2 \cdot 4 * * *$ & $0 \cdot 1$ \\
\hline Bound water $(\mathrm{g} / \mathrm{g}$ dry $w \mathrm{t}) \ddagger$ & $1 \cdot 2$ & $0 \cdot 1$ & $1 \cdot 1$ & $0 \cdot 1$ & $1.5^{*}$ & $0 \cdot 1$ \\
\hline Total water $(\mathrm{g} / \mathrm{d})$ & $2 \cdot 0$ & 02 & $3 \cdot 3 * *$ & $0 \cdot 1$ & $3 \cdot 6 * * *$ & $0 \cdot 2$ \\
\hline Bound water $(\mathrm{g} / \mathrm{d}) \ddagger$ & $1 \cdot 5$ & $0 \cdot 2$ & $2 \cdot 4^{* *}$ & $0 \cdot 1$ & $2 \cdot 3^{* *}$ & $0 \cdot 1$ \\
\hline DAPA $(\mu \mathrm{mol} / \mathrm{g}$ dry $w \mathrm{t}) \S$ & $4 \cdot 7$ & $0 \cdot 1$ & $3 \cdot 4 *$ & 0.1 & $8 \cdot 1^{* *}$ & $0 \cdot 1$ \\
\hline SCFA $(\mu \mathrm{mol} / \mathrm{g}$ dry wt) & 76 & 2 & 94 & 9 & $152 * *$ & 23 \\
\hline
\end{tabular}

Mean values were significantly different from those for basal diet: ${ }^{*} P<0.05,{ }^{* *} P<0.01,{ }^{* * *} P<0.001$ (unpaired $t$ test).

$\dagger$ For details of procedures, see pp. 915-916.

$\ddagger$ After $72 \mathrm{~h}$ at 2 atm pressure.

$\S$ SEM of $\log$ transformed data.

frozen at $-20^{\circ}$ and then freeze-dried. The dry weight of sample was determined by subtracting the weight of both the vial and freeze-dried dialysis bag. Bound water was calculated from the loss in weight after exposure to 2 and $4 \mathrm{~atm}$.

Each determination was done in duplicate. The WHC (or bound water) was expressed as $g$ water held per $g$ dry weight of sample.

\section{Statistical analysis}

Results were analysed using the unpaired $t$ test and means were considered different at $P<0.05$.

\section{RESULTS}

The body-weight gains over the $28 \mathrm{~d}$ (mean with SE) on the basal and pectin- and bransupplemented diets were 140 (SE 7), 94 (SE 4) and 120 (SE 5) g respectively. All rats gained weight but the increase was significantly greater on the basal diet compared with pectin ( $P$ $<0.001)$ or bran $(P<0.01)$.

As freezing the stool and caecal contents may alter the WHC, the effect of such a method 
Table 4. The influence of wheat bran and pectin $(100 \mathrm{~g} / \mathrm{kg})$ on wet and dry weight, total and bound water, short-chain fatty acids (SCFA) and 2,6-diaminopimelic acid (DAPA) in the caecum $\dagger$

(Mean values with their standard errors for six observations)

\begin{tabular}{|c|c|c|c|c|c|c|}
\hline \multirow[t]{2}{*}{ Diet... } & \multicolumn{2}{|c|}{ Basal } & \multicolumn{2}{|c|}{+ Bran } & \multicolumn{2}{|c|}{+ Pectin } \\
\hline & Mean & $\mathrm{SE}$ & Mean & $\mathrm{SE}$ & Mean & SE \\
\hline Wet wt (g) & $2 \cdot 9$ & $0 \cdot 3$ & $3 \cdot 0$ & $0 \cdot 2$ & $5 \cdot 5^{* *}$ & 0.7 \\
\hline Dry wt $(g)$ & 0.6 & $0 \cdot 1$ & $0 \cdot 7$ & $0 \cdot 1$ & $1 \cdot 0^{*}$ & $0 \cdot 1$ \\
\hline Total water (g/g dry wt) & $3 \cdot 8$ & $0 \cdot 17$ & $3 \cdot 5$ & 0.05 & $4 \cdot 7^{* *}$ & $0 \cdot 15$ \\
\hline Bound water $(\mathrm{g} / \mathrm{g} \text { dry } w \mathrm{t})_{+}^{+}$ & $1 \cdot 2$ & $0 \cdot 2$ & 1.6 & 0.2 & 1.4 & 0.2 \\
\hline Total water ( $\mathrm{g}$ per caecum) & $2 \cdot 3$ & $0 \cdot 2$ & $2 \cdot 4$ & $0 \cdot 2$ & $4 \cdot 6^{*}$ & 0.5 \\
\hline Bound water (g per caecum) $\ddagger$ & $0 \cdot 7$ & $0 \cdot 1$ & $1 \cdot 2^{* *}$ & $0 \cdot 1$ & $1 \cdot 4^{* *}$ & $0 \cdot 2$ \\
\hline DAPA $(\mu \mathrm{mol} / \mathrm{g}$ dry $w \mathrm{t})$ & $3 \cdot 5$ & 0.6 & 2.6 & 0.6 & $4 \cdot 4^{*}$ & 0.7 \\
\hline SCFA ( $\mu \mathrm{mol} / \mathrm{g}$ dry wt) & $769^{*}$ & 55 & 511 & 33 & 487 & 51 \\
\hline
\end{tabular}

Mean values were significantly different from those for basal diet: ${ }^{*} P<0.05,{ }^{* *} P<0.01$ (unpaired $t$ test)

$\dagger$ For details of procedures, see pp. 915-916.

$\ddagger$ After $72 \mathrm{~h}$ at $2 \mathrm{~atm}$ pressure.

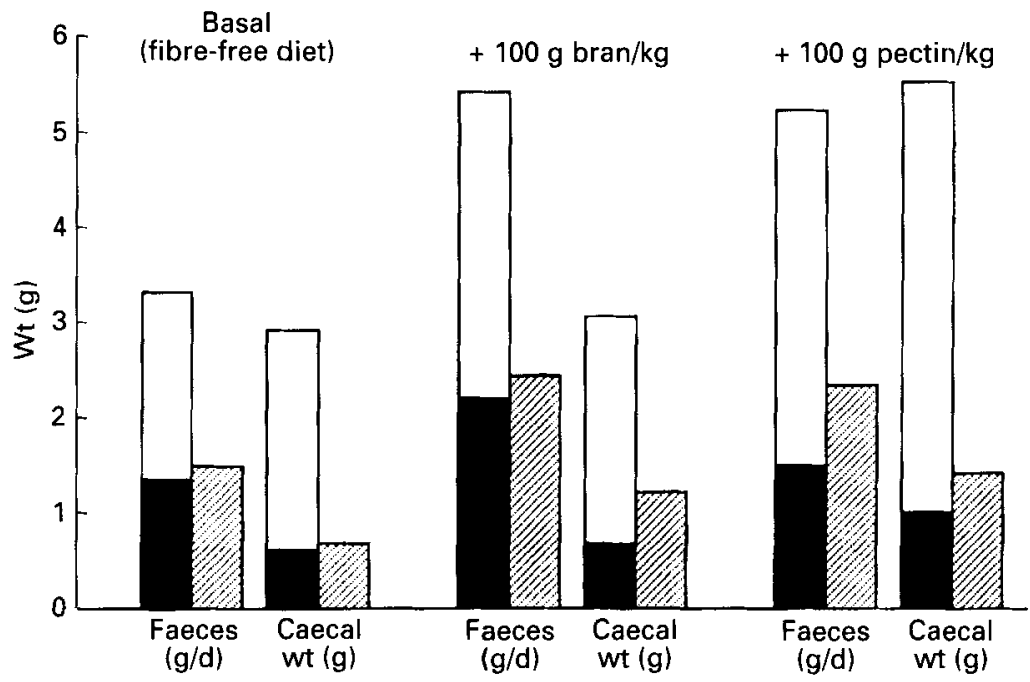

Fig. 1. Distribution of water in faeces and caecal contents from rats previously fed on a basal (fibre-free) diet supplemented with $100 \mathrm{~g}$ bran or $100 \mathrm{~g}$ pectin $/ \mathrm{kg}$. ( $\square$ ), Water; $(\mathbf{D})$, dry weight; ( $\Delta$ ), bound water. For details of procedures, see pp. 914-916.

of storage was examined comparing identical specimens, fresh and frozen at $-20^{\circ}$ for $3 \mathrm{~d}$. The medium range of percentage difference between paired samples $(n 10)$ was 1 (range $0-13$ ). One-way analysis of variance showed no significant differences $(P=0.56)$.

The WHC of wheat bran and pectin before ingestion are shown in Table 2. At $2 \mathrm{~atm}$, pectin held approximately four times as much water as wheat bran. The WHC of pectin was reduced when exposed to $4 \mathrm{~atm}(P<0.001)$ compared with the $2 \mathrm{~atm}$ value. However, wheat bran had a similar WHC at both pressures.

Pectin increased faecal wet weight, but had no influence on faecal dry weight (Table 3 ). Bran increased both wet and dry faecal weights. The total faecal water increased on both 
supplements as did the total bound water. The bound water ( $\mathrm{g} / \mathrm{g}$ dry weight) increased significantly in the pectin-supplemented animals but not in the other two groups (Table 3 ).

Pectin increased the wet and dry weights of caecal contents. Bran had no influence on wet or dry weights of caecal contents. Pectin increased the total water held within the caecum and the water held per $g$ dry weight (Table 4). The bound water held against the suction pressure did not increase when expressed on a per g dry weight basis on either of the supplemented diets, but the total amount of bound water held per caecum increased significantly on both diets. By difference the amount of free caecal water (total-bound) was much greater on the pectin-supplemented diet (Table 4).

Results for the distribution of water are summarized in Fig. 1. Tables 3 and 4 show the results for DAPA and SCFA concentrations in caecal contents and faeces. Pectin significantly increased the concentration of DAPA in caecal contents and faeces and the concentration of SCFA in faeces in animals given the pectin supplement.

\section{DISCUSSION}

The present study was designed to simulate the removal of water from colonic contents by using dialysis membranes and PEG solution to create an osmotic gradient of $2 \mathrm{~atm}$. This gives a measure of the water bound by the colonic contents and faeces which would be unavailable for absorption under normal conditions. The pressure value of $2 \mathrm{~atm}$ i.e. $89 \mathrm{mosm} / \mathrm{kg}$, was chosen for a number of reasons. It is not an unreasonable value in that the human colon transports water against osmolar gradients of more than $50 \mathrm{mosm} / \mathrm{kg}$. Even greater osmotic gradients of more than $50 \mathrm{mosm} / \mathrm{kg}$ are required to drive water through channels of limited permeability (Billich \& Leviton, 1979). When the WHC of fibre was measured against varying osmotic pressures the WHC decreased up to pressures of 2 atm but further increments had no effects (Robertson \& Eastwood, 1981). This is confirmed in the present study, as shown in Table 2, which further substantiates the validity of using $2 \mathrm{~atm}$ pressure.

Human faeces contain approximately $75 \%$ water, of which about $80-90 \%$ is believed to be either contained within bacterial cells or bound by the undigested fibre (Stephen \& Cummings, $1980 \mathrm{c}$ ). The remainder of the total water is free and available for absorption. Water is passively absorbed from the colon along osmotic gradients created mainly by the movement of SCFA (Phillips \& Giller, 1973).

In the present study the increase in dry stool weight after feeding bran was probably caused by an increased output of undigested fibre (Nyman \& Asp, 1982). Pectin (100 g/kg) did not significantly increase dry stool weight but the increased concentration of DAPA would indicate a greater contribution of bacteria to the stool mass. The DAPA contents of bacteria vary, consequently the increases could represent a change in the types of bacteria with the development of a bacterial mass with a richer DAPA content, i.e. a change in the flora.

Although the total water content of faeces from rats fed on either wheat bran or pectin was similar, water was distributed in different ways. Bran increased total water but did not change its distribution.

Wheat bran did not increase the amount of water held on a per $\mathrm{g}$ dry faeces per $\mathrm{d}$ basis in either the in vivo (\% water) or in vitro (WHC) measurements. There are reports which have demonstrated that the ingestion of bran-supplemented diets does not increase faecal water content (Slavin et al. 1985). The WHC of bran is no greater than that of the other faecal components. In the present study wheat bran had a higher WHC before it was consumed by the rat compared with the residual WHC in the faeces. Wheat bran contained only $38 \mathrm{~g}$ fibre $/ \mathrm{kg}$ and up to $40 \%$ of this may have been fermented (Hove \& King, 1979; Nyman \& Asp, 1982), which may explain the lower WHC of the residual material in the faeces. 
Pectin increased the proportion of faecal water relative to dry weight, increasing both the bound and free components. McBurney et al. (1985) and Stephen \& Cummings (1980) have suggested that pectin is completely fermented and that the resultant stool bulk is primarily from microbial organic matter. Fermentable fibres such as pectin increase faecal water by increasing bacterial mass (Stephen \& Cummings, $1980 \mathrm{c}$ ). Bacteria consist of about $80 \%$ intracellular water, which is unavailable for absorption. The WHC of unfermented dietary fibre is of greater importance to faecal bulking than bulking produced by bacterial proliferation. On the other hand it has been suggested that $25 \%$ of pectin survives fermentation (Hove \& King, 1979; Nyman \& Asp, 1982). It is possible that some of the bound water in the present study may be associated with unfermented pectin as this was fed as a supplement $(100 \mathrm{~g} / \mathrm{kg})$.

The present methods of separating NSP and bacteria are quite exacting. Such methods would give further insights into this question.

The factors, chemical and physical, which influence post-fermentation WHC of intestinal contents are yet to be clearly established (Armstrong et al. 1990).

The ability of the colonic contents to bind water against the dehydrating forces of the colon is important. However, there may be factors other than bacterial and fibre WHC which determine total faecal water, especially the free, unbound water. Pectin increased the total water and free water content of the stool. The reasons for this are not apparent but there are several possible mechanisms. An increase in osmotically active material following fermentation may have led to a greater retention of water (Table 1). Caecal contents have a higher water content than fresh faeces but a similar amount of bound water. Factors which influence the absorption of this extra free water as the contents move along the colon will determine the free water content of the stool. The caecum is an important site for the production and absorption of SCFA. The influence of SCFA on stool water has not yet been fully explored. Hellendoorn (1969) originally postulated that SCFA production increased stool output by acting as an osmotic load. More recent work has shown that SCFA are readily absorbed from the colon, thus minimizing a possible role in determining stool output (McNeil et al. 1978). However, Sakata (1987) has shown that SCFA correlate with the free water component of the colonic contents and others have shown a correlation between faecal SCFA and wet stool weight (Ross et al. 1983). In our study pectin increased the faecal concentration of SCFA as well as increasing the free stool water. Apart from an osmotic action, SCFA may affect stool water indirectly by influencing colonic motility and transit. SCFA have been shown to stimulate contractions in rat colonic strips in vitro (Yajima, 1985). The role of SCFA in determining stool water needs to be reassessed.

The absorption of available water will depend to some extent on the contact time between intestinal contents and the colonic mucosa. Agents that increase colonic propulsion may increase faecal water by reducing the time available not only for absorption of water but also for the fermentation of unabsorbed carbohydrate. Factors which may stimulate colonic propulsion include distension (Chauve, 1976), hydroxy fatty acids and bile acids (Falconer et al. 1980).

There appear to be differing mechanisms of the action of bran and pectin on faecal water. Each is equally effective in the rat in increasing stool weight, wheat bran having less initial WHC and stimulating less bacterial growth. It is possible that bran may alter colonic transit by predominantly motor effects rather than by affecting colonic bacteria.

In summary, wheat bran and pectin both increased stool output but by different mechanisms which resulted in a different distribution of stool water. Wheat bran had a moderate capacity to bind water and did not change faecal WHC, but since it was only partly fermented it increased colonic content turnover and contributed considerably to the total faecal water output without changing water distribution. 
Pectin increased the proportion of water in the faeces. There may be a residual unfermented fraction and also free water by an unknown mechanism which possibly relates to continuous metabolism of the pectin throughout the colon.

\section{REFERENCES}

Armstrong, E. A., Brydon, W. G. \& Eastwood, M. (1990). Fiber metabolism and colonic water. In Dietary Fiber, pp. 179-186 [D. Kritchevsky, C. Bonfield and J. W. Anderson, editors]. New York: Plenum Press.

Billich, C. O. \& Leviton, R. (1979). Effects of sodium concentration and osmolality on water and electrolyte absorption from the intact colon. Journal of Clinical Investigation 48, 1336-1347.

Burkitt, D. P., Walker, A. R. P. \& Painter, N. S. (1972). Effect of dietary fibre on stools and transit times, and its role in the causation of disease. Lancet ii, 1408-1412.

Chauve, A. (1976). Intraluminal pressures during perfusion of the human colon in situ. Gastroenterology 70 , 336-340.

Czerkawski, J. W. (1974). Methods for determining 2-6-diaminopimelic acid and 2-aminoethylphosphonic acid in gut contents. Journal of the Science of Food and Agriculture 25, 45-55.

Eastwood, M. A., Brydon, W. G., Baird, J. D., Elton, R. A., Smith, J. H. \& Pritchard, J. L. (1982). Fecal weight and composition, serum lipids, and diet among subjects aged 18-80 years not seeking health care. American Journal of Clinical Nutrition 40, 628-634.

Eastwood, M. A., Robertson, J. A., Brydon, W. G. \& MacDonald, D. (1983). Measurement of water-holding properties of fibre and their faecal bulking ability in man. British Journal of Nutrition 50, 539-547.

Englyst, H. N. \& Cummings, J. H. (1988). Vitamins and other nutrients. Improved method for measurement of dietary fiber as non-starch polysaccharides in plant foods. Journal of the Association of Official Analytical Chemists 71, 808-814.

Falconer, J. D., Smith, A. N. \& Eastwood, M. A. (1980). The effects of bile acids on colonic motility in the rat. Quarterly Journal of Experimental Physiology 85, 135-141.

Hellendoorn, E. W. (1969). Intestinal effects following ingestion of beans. Food Technology 23, 87-93.

Hove, E. L. \& King, S. (1979). Effect of pectin and cellulose on growth, feed efficiency and protein utilisation, and their contribution to energy requirements and caecal VFA in rats. Journal of Nutrition 109, 1274-1278.

McBurney, M. I., Horvath, P. J., Jeraci, J. L. \& Van Soest, P. J. (1985). Effect of in vitro fermentation using human faecal inoculum on the water-holding capacity of dietary fibre. British Journal of Nutrition 53, 17-24.

McNeil, N. I., Cummings, J. H. \& James, W. P. T. (1978). Short chain fatty acid absorption by the human large intestine. Gut 18, 819-822.

Nyman, M. \& Asp, N.-G. (1982). Fermentation of dietary fibre components in the rat intestinal tract. British Journal of Nutrition 47, 357-366.

Phillips, S. F. \& Giller, J. H. (1973). The contribution of the colon to electrolytes and water conservation in man. Journal of Laboratory and Clinical Medicine 8, 733-746.

Robertson, J. A. \& Eastwood, M. A. (1981). A method to measure the water-holding properties of dietary fibre using suction pressure. British Journal of Nutrition 46, 247-255.

Ross, A. H. McL., Eastwood, M. A., Brydon, W. G., Anderson, J. R. \& Anderson, D. M. W. (1983). A study of the effects of dietary gum arabic in humans. American Journal of Clinical Nutrition 37, 368-375.

Sakata, T. (1987). Short-chain fatty acids and water in the hindgut contents and faeces of rats after hindgut bypass surgery. Scandinavian Journal of Gastroenterology 22, 961-968.

Siljestrom, M. \& Asp, N.-G. (1985). Resistant starch formation during baking. Effect of baking time and temperature and variations on the recipe. Zeitschrift für Lebensmitteluntersuchung und -forschung 181, 4-8.

Slavin, J. L., Nelson, N. L., McNamara, E. A. \& Cashmere, K. (1985). Bowel function of healthy men consuming liquid diets. Journal of Parenteral and Enteral Nutrition 9, 317-321.

Spiller, G. A., Chernoff, M. C., Hill, R. A., Gates, J. E., Nassar, J. J. \& Shipley, E. A. (1988). Effect of purified cellulose, pectin and a low residue diet on faecal volatile fatty acids, transit-time and faecal weight in humans. American Journal of Clinical Nutrition 33, 754-759.

Stephen, A. M. \& Cummings, J. H. (1980a). Water-holding by dietary fibre in vitro and its relationship to faecal output in man. Gut 20, 722-729.

Stephen, A. M. \& Cummings, J. H. (1980b). The microbial contribution to human faecal mass. Journal of Medical Microbiology 13, 45-56.

Stephen, A. M. \& Cummings, J. H. (1980c). Mechanism of action of dietary fibre in the human colon. Nature 284, 283-284.

Tomlin, J. \& Read, N. W. (1988). Laxative properties of indigestible plastic particles. British Medical Journal 297, $1175-1176$.

Yajima, T. (1985). Contractile effects of short-chain fatty acids on the isolated colon in the rat. Journal of Physiology 368, 667-678. 